\title{
Tendencia actual de la responsabilidad estatal en procesos de privación injusta de la libertad proferidos por la Sección Tercera del Consejo de Estado en los años 2016 a 2017
}

Current trend of state responsibility in processes of unjust deprivation of liberty proffered by the Third Section of the Council of State in the years 2016-2017

Tendência atual da responsabilidade estatal em processos de privação da liberdade injustificada proferidos pela Seção Terceira do Conselho de Estado de 2016 a 2017

\section{Andrea Del Pilar Ramírez Rivas ${ }^{1}$}

Recibido: 24 de septiembre de 2019

Aprobado: 15 de octubre de 2019

Publicado: 25 de noviembre de 2019

Cómo citar este artículo:

Andrea Del Pilar Ramírez Rivas. Tendencia actual de la responsabilidad estatal en procesos de privación injusta de la libertad proferidos por la Sección Tercera del Consejo de Estado en los años 2016 a 2017. DIXI 30, julio-diciembre 2019, 1-16.

DOI: https://doi.org/10.16925/2357-5891.2019.02.04

Artículo de investigación. https://doi.org/10.16925/2357-5891.2019.02.04

1 Abogada de la Universidad Cooperativa de Colombia con tesis meritoria. Jefe del Departamento Jurídico en Inversiones y Construcciones de Colombia SAS.

Correo electrónico: andyrr_1981@hotmail.com 


\section{Resumen}

Objeto: en Colombia se observa el problema reiterado de las detenciones masivas; y se han vuelto cada vez más frecuentes las prácticas arbitrarias y la utilización inadecuada del poder al privar a un ciudadano de la libertad. El Estado social de derecho está fundado en la dignidad de la persona humana, por lo que no puede estructurarse ni funcionar con base en el desconocimiento de los derechos de los particulares.

Metodología: definir las líneas jurisprudenciales y el alcance de la responsabilidad patrimonial en las acciones de reparación directa en procesos de privación injusta de la libertad en la Sección Tercera del Consejo de Estado adquiere importancia desde el punto de vista de las ciencias jurídicas, por cuanto se requiere tener una claridad conceptual sobre el actual reconocimiento de los perjuicios extrapatrimoniales en Colombia.

Hallazgos: esto le está ocasionando problemas al Estado, entre ellos las demandas por responsabilidad estatal, generando un detrimento patrimonial.

Conclusiones: la sujeción de los procedimientos legales a los principios fundamentales del derecho son la vía más segura para evitar fallas o vulneraciones de derechos que a posteriori generen la obligación estatal de asumir responsabilidades y reparar daños por vías de indemnización de perjuicios, bien sean estos patrimoniales o extrapatrimoniales.

Palabras clave: Estado social de derecho, privación injusta de la libertad, reparación directa, responsabilidad estatal.

\section{Abstract}

Purpose: In Colombia, there is a recurring problem of mass detentions, and arbitrary practices and inappropriate use of power have become increasingly frequent when a citizen is deprived of his or her liberty. The social state under the rule of law is founded on the dignity of the human person and cannot therefore be structured or operate based on ignorance of the rights of individuals.

Methodology: Defining the lines of jurisprudence and the scope of patrimonial responsibility in actions for direct reparation in processes of unjust deprivation of liberty in the Third Section of the Council of State acquires importance from the point of view of the legal sciences. This is because it is necessary to have conceptual clarity on the current recognition of extra-patrimonial damages in Colombia.

Findings: This is causing problems for the state, including claims for state responsibility, generating a patrimonial detriment.

Conclusions: Subjecting legal procedures to the fundamental principles of law is the safest way to avoid failures or violations of rights that subsequently generate the state's obligation to assume responsibility and repair damages by means of compensation for damages, whether these are patrimonial or extra-patrimonial.

Keywords: Social state under the rule of law, unjust deprivation of liberty, direct reparation, state responsibility.

\section{Resumo}

Objeto: na Colômbia, observa-se o problema reiterado das detenções massivas. As práticas arbitrárias e a utilização inadequada do poder têm se tornado cada vez mais frequentes, ao privar o cidadão da liberdade. 0 Estado social de direito está fundado na dignidade da pessoa humana, razão pela qual não pode ser estruturado nem funcionar com base no desconhecimento dos direitos dos particulares.

Metodologia: definir as linhas jurisprudenciais e o alcance da responsabilidade patrimonial nas ações de reparação direta em processos de privação da liberdade injustificada na Seção Terceira do Conselho de Estado ganha importância do ponto de vista das ciências jurídicas, portanto se requer ter clareza conceitual sobre o atual reconhecimento dos prejuízos extrapatrimoniais na Colômbia. 
Achados: tal situação está ocasionando problemas ao Estado, entre eles as demandas por responsabilidade estatal, o que gera um detrimento patrimonial.

Conclusões: a sujeição dos procedimentos legais aos princípios fundamentais do direito é a via mais segura para evitar falhas ou violações de direitos que a posteriori gerem a obrigação estatal de assumir responsabilidades e reparar danos por meio de indenização de prejuízos, patrimoniais ou extrapatrimoniais.

Palavras-chave: Estado de direito social, privação injusta de liberdade, reparação direta, responsabilidade estatal.

\section{INTRODUCCIÓN}

La responsabilidad patrimonial del Estado derivada de la privación injusta de la libertad se fundamenta jurisprudencialmente en las sentencias de unificación proferidas por la Sección Tercera del Consejo de Estado, a través de tres fases o etapas: la primera es "la teoría de la tesis subjetiva o restrictiva"; la segunda fase es "por error judicial", en la que la víctima debe demostrar lo injusto de su detención; y la fase tercera es el "in dubio pro reo", en el que se determina que la responsabilidad patrimonial del Estado por privación injusta de la libertad se puede derivar cuando el proceso penal termina con sentencia absolutoria.

La privación injusta de la libertad, como título autónomo de imputación de la responsabilidad patrimonial del Estado por el funcionamiento de la administración de justicia, tiene por fuente primaria el artículo 90 de la Constitución Política de Colombia, el cual es aplicable con o sin ley que desarrolle esta forma de responsabilidad. Inicialmente, el Consejo de Estado confundió el error judicial y el funcionamiento defectuoso de la administración de justicia con la privación injusta de la libertad; luego consideró objetiva la responsabilidad del Estado por la privación injusta de la libertad y la diferencia del error judicial; y hoy considera que la reclamación de perjuicios se funda en la antijuridicidad del daño sufrido por la víctima, en tanto que esta no tiene la obligación jurídica de soportarlo.

El problema consiste en que el sistema judicial no debe buscar cárcel para todos, debe haber seguridad jurídica sin impunidad; una renovación de la política criminal. Una reforma judicial efectiva que permita el deber de reparación por privación injusta de la libertad como una exigencia constitucional directa, porque el actor pasivo no estaba en la obligación de soportar el daño que el Estado le irrigó, el cual debe ser considerado como antijurídico. Esta calificación determina lo consecuente para la Administración Pública de resarcir a la parte actora que sufrió el daño o ha sido víctima de este hecho, motivo por el cual resulta de extrema importancia identificar 
la tendencia actual de la responsabilidad estatal en procesos de privación injusta de la libertad proferidos por la Sección Tercera del Consejo de Estado en los años 2016 a 2017.

Definir las líneas jurisprudenciales y el alcance de la responsabilidad patrimonial en las acciones de reparación directa en procesos de privación injusta de la libertad en la Sección Tercera del Consejo de Estado, adquiere importancia desde el punto de vista las ciencias jurídicas, por cuanto se requiere tener una claridad conceptual sobre el actual reconocimiento de los perjuicios extrapatrimoniales en Colombia.

La tendencia o postura jurisprudencial que actualmente ha tomado la Sección Tercera del Consejo de Estado frente a la privación injusta de la libertad procede cuando quien ha sido privado de la libertad tiene derecho a ser indemnizado acreditando que el Estado obró inadecuadamente, esto es, cuando demuestra que la captura no debió decretarse o que la retención no debió ejecutarse; condenando al Estado a pagar una serie de daños y perjuicios morales por la detención de un ciudadano que no está en el deber legal de soportarlo a consecuencia de la falla en el servicio y el defectuoso funcionamiento de la administración de justicia.

El problema de investigación se centra en que actualmente la Sección Tercera del Consejo de Estado ha venido desarrollando sentencias de unificación jurisprudencial en las que la responsabilidad del Estado se determina con fundamento en lo dispuesto en el artículo 90 de la Carta Política, sin limitarse a la falla en el servicio como presupuesto de la responsabilidad, por lo cual el derecho a la indemnización en estos casos no depende de acreditar que la captura fue ilegal. Entonces, el Estado debe indemnizar, porque cuando detiene a un ciudadano y luego lo absuelve del delito que le imputó, se estima que le causó un daño antijurídico: un daño que reviste especial gravedad ya que el ciudadano no está obligado a soportarlo como una carga pública normal impuesta a todos por vivir en sociedad. El Consejo de Estado confunde el error judicial y el funcionamiento defectuoso de la administración de justicia con la privación injusta de la libertad.

En esta primera fase, el Consejo de Estado confunde los distintos títulos de imputación de la responsabilidad patrimonial del Estado con el funcionamiento de la administración de justicia, lo que se advierte con el trato indiferenciado que le da a cada uno de estos, englobando en una misma definición las distintas especies de responsabilidad judicial, sin percatarse que son diferentes, pues una es la responsabilidad por error judicial y por funcionamiento anormal de la administración de justicia, y otra es la responsabilidad por privación injusta de la libertad, a la que somete impropiamente a los presupuestos subjetivos del error judicial, en el equivocado entendido de que esta noción es el género y de la cual la prisión provisional injusta es la especie. 
En apoyo de mi aserto, tenemos jurisprudencialmente en Consejo de Estado, Sala de lo Contencioso Administrativo, Sección Tercera, Sentencia del 01 de octubre de 1992, Expediente 7058: "Si bien el Consejo de Estado se ha mostrado renuente a declarar la responsabilidad del Estado por falla del servicio judicial, considera la Sala que tal posición jurisprudencial no puede ser tan inflexible ni volver la espalda a determinadas realidades de equidad y justicia".

Se puede observar entonces que, en sus primeras posiciones, la responsabilidad por la actuación errada o injusta de los administradores de justicia, aun siendo consecuencia del obrar individual del funcionario, lleva inevitablemente a la responsabilidad y obligación del Estado de reparar los daños generados por el actuar de quien le representa. Pero manifiesta claramente que las acciones o decisiones del operador de justicia deben ser abiertamente contrarias a derecho, que se debe probar que tal decisión es errada, y de esta manera se dará paso al reconocimiento de la obligación del Estado de reparar a quien estuvo privado de la libertad por causa de un proceso o sentencia errada. Esta obligación es un derecho para los asociados que puedan verse afectados o dañados por este actuar y el conocimiento de tal posibilidad es también un derecho para ellos.

El Consejo de Estado no solo exige una conducta fallida de la administración de justicia para el surgimiento de la responsabilidad patrimonial del Estado, sino también la presencia de una decisión judicial abiertamente contraria a derecho, como requisito sine qua non, para que haya lugar a juicio de responsabilidad. Esta confusión conceptual lleva al Alto Tribunal de lo Contencioso Administrativo a exigir los presupuestos del error judicial para la procedencia de la indemnización por la prisión provisional injusta, en el entendido equivocado de que esta es una especie de aquel.

En efecto, en la Sentencia de septiembre 15 de 1994 del Consejo de Estado, Sala de lo Contencioso Administrativo, Sección Tercera, Exp. 9391, se hace depender la responsabilidad por privación injusta de la libertad (en el art. 414 del Decreto Ley 2700) del error en la decisión judicial que ordena la detención, o dicho en otros términos, por el desacato del deber que tiene el funcionario judicial de proferir sus resoluciones conforme a derecho, posición que también se aparta de la regla, pues el título de imputación no está erigido sobre la ilegalidad de la conducta del juez.

Esta interpretación, en mi sentir, salvo mejor criterio, solo se explica por la novedad de la institución para entonces y por la tradición jurisprudencial que venía del Consejo de Estado en vigencia de la Constitución Política de 1886. Pero tampoco podemos justificar tamaño desatino debido a la expedición de la Ley 270 de 1996, Ley Estatutaria de la Administración de Justicia, que diferenció los títulos de imputación; por lo que estimo cuestionable que después de esta reserva legal el Consejo 
de Estado siguiera sosteniendo su tesis de la exigencia de decisiones contrarias a derecho o abiertamente arbitrarias como presupuesto para configurar la privación injusta de la libertad.

Si bien la expedición de la Ley 270 de 1996 es posterior a la posición que utilizo para demostrar la confusión del colegiado administrativo, se esperaba del mismo una más profunda comprensión del verdadero fundamento de la responsabilidad objetiva frente a la privación injusta de la libertad. No sujetando la injusticia de la privación a la injusticia o errada decisión del juez en su sentencia.

\section{ANTECEDENTES QUE DIERON ORIGEN A LA UTILIZACIÓN DE LA RESPONSABILIDAD PATRIMONIAL POR PRIVACIÓN INJUSTA DE LA LIBERTAD}

La responsabilidad patrimonial del Estado en nuestro país antes de la Constitución Política de 1991 se caracterizó por tener un origen pretoriano, pues ante la ausencia (tanto en la Carta Política de 1886 como en la ley) de un principio general de responsabilidad extracontractual del Estado, esta figura fue desarrollada por la jurisprudencia de la Corte Suprema de Justicia y del Consejo de Estado, que con base en principios constitucionales, en normas especiales y generales (Código Civil) que consagraban los eventos de responsabilidad extracontractual de la administración pública, y nutrida también de la doctrina y jurisprudencia francesa, se encargaron de fijar fundamentos y pautas para su procedencia, todo lo cual sirvió de antecedente a la consagración constitucional de la responsabilidad patrimonial del Estado en la Carta Política de 1991.

La responsabilidad patrimonial del Estado comprendía únicamente la de la Administración Pública, pero no así la de los demás poderes públicos del Estado, pues en relación con la responsabilidad por el funcionamiento de la administración de justicia, el Consejo de Estado adoptó la tesis de la irresponsabilidad del Estado-juez, aduciendo la ausencia de reserva legal que permitiera la reclamación al Estado por error judicial, como sí existía en relación con los jueces (art. 40 del Decreto 1400 de 1970, que le atribuía una responsabilidad personal por esta causa) y además fundada en el respeto al principio de la intangibilidad de la cosa juzgada que impide que las decisiones judiciales ejecutoriadas sean cuestionadas por otros jueces (principio de seguridad jurídica), razón por la que se estimó que el error judicial era un riesgo que los particulares debían soportar. 
Sin embargo, a partir de 1991 se introdujo un cambio fundamental, ya que la Carta Política de ese año estableció en su artículo 90 un principio general de responsabilidad patrimonial del Estado, tanto de naturaleza contractual como extracontractual, fundamentado en la noción de daño antijurídico, que es aquel que la víctima no tiene la obligación de soportar.

Antes de adentrarme en el estudio de las normas internas que se ocupan de la regulación de la materia en nuestro ordenamiento legal positivo, debo indicar que estas son expresión de la tendencia universal contenida en instrumentos internacionales de derechos humanos que hacen parte del bloque de constitucionalidad, según los cuales se propende a la obligación estatal de reparar los perjuicios causados por la detención o prisión preventiva injusta.

Los autores Ricardo Hoyos Duque, María Victoria Zambrano y Luis Fernando Jaramillo Bedoya, en su artículo "Responsabilidad del Estado por la privación injusta de la libertad"1, analizan la jurisprudencia del Consejo de Estado identificando tres posiciones desarrolladas a través del tiempo.

La primera posición es de tipo subjetivo, exigiendo para la determinación de la responsabilidad que haya una conducta fallida de la administración de justicia y que la sentencia o decisión judicial sea contraria a derecho. La segunda posición es de tipo objetivo, sujeta a lo que determinaba el Código de Procedimiento Penal de 1991, siendo tres las causales establecidas para que proceda la declaración de responsabilidad estatal en los casos en que una persona habiendo sido privada de la libertad como consecuencia de una medida de aseguramiento posteriormente sea liberada por decisión judicial que determine:

- $\quad$ Que el hecho investigado no ocurrió, que el imputado no lo cometió, que el hecho investigado no constituye delito (atipicidad).

- Se tiene por objetiva ya que no se examina la conducta del operador judicial en el sentido de determinar si esta fue errada, injusta, arbitraria o abiertamente ilegal.

La tercera posición es de tipo objetivo también, y es la que se aplica actualmente fundamentada en el artículo 90 de la Constitución Nacional vigente, identificando lo injusto de la detención de quien posteriormente fuera exonerado de responsabilidad en la ausencia de obligación legal en cabeza del imputado de soportar la

1 Véase Ricardo Hoyos Duque, María Victoria Zambrano y Luis Fernando Jaramillo Bedoya. Responsabilidad del Estado por la privación injusta de la libertad. REVISTA PROLEGÓMENOS, DERECHOS Y VALORES 9. Enero-junio 2006. 
vulneración de su derecho a la libertad. Esta no obligación se establece a partir de la no obligación de la generalidad de las personas de sujetarse a la privación de su derecho sin una causa justificada, esto es, ser responsables de la comisión de un hecho punible.

El doctrinante Joaquín García Morillo, en su libro Los derechos de la libertad², refiriéndose a la libertad personal acertadamente expone que los motivos para privar a una persona de la libertad deben ser establecidos no por cualquier vía, sino por medio de una ley, y acertadamente expone que:

No basta, sin embargo, cualquier norma: es preciso que la norma jurídica que determina los supuestos en que procede la privación de la libertad sea una ley. Esta exigencia tiene fundamento evidente: desde el momento en que la libertad individual es asumida por la sociedad como un principio básico de la organización de su convivencia social, es solo la propia sociedad la que puede determinar los casos que dan lugar a la quiebra de ese principio básico y esa expresión de la voluntad general de la sociedad tiene lugar a través de la ley. Constitucionalmente, esa exigencia se plasma en otra: la de que sean los representantes del pueblo libremente escogidos los que determinen las causas de privación de libertad. [...] La determinación previa de las causas de privación de libertad tiene además otra razón material, la de otorgar seguridad jurídica a los ciudadanos, esto es, que los ciudadanos sepan de antemano qué conductas pueden suponer la privación de un bien básico como la libertad. Se trata, con ello, de desterrar la arbitrariedad.

\section{Sobre la tendencia sobre responsabilidad estatal por privación injusta de la libertad en España}

La responsabilidad estatal por privación injusta de la libertad en España está regulada de manera específica en el art 294.1 de la Ley Orgánica del Poder Judicial, que se lee: "Tendrán derecho a indemnización quienes, después de haber sufrido prisión preventiva, sean absueltos por inexistencia del hecho imputado o por esta misma causa haya sido dictado auto de sobreseimiento libre, siempre que se le hayan irrogado perjuicios". Es claro entonces que se refiere estrictamente a esas personas que vieron vulnerado su derecho a la libertad, pero que han sido absueltos por inexistencia del

2 Véase Joaquín García Morillo. Los DERECHOs DE LA LIBERTAD. Tirant lo Blanch. (1995). 
hecho imputado o que se haya dictado sobreseimiento libre (la Fiscalía desiste de la investigación) por la misma razón.

Según lo anterior, son requisitos para que proceda la indemnización los siguientes:

1. Que el sujeto de la investigación haya sido privado preventivamente de su libertad.

2. Que su situación jurídica se haya resuelto con sentencia absolutoria o auto de sobreseimiento libre por inexistencia del hecho (en ambas decisiones).

3. Que el sujeto haya sufrido perjuicios con motivo de la privación de su libertad.

A través de sentencias del Tribunal Europeo de Derechos Humanos, se ha buscado una interpretación más amplia de este literal normativo, en el entendido de reconocer la responsabilidad estatal y la obligación de indemnizar en los casos en que se declare inocente a quien haya sido privado de su libertad por no haberse podido probar su participación en el hecho investigado. Situación que no ha ocurrido, pues el Tribunal Supremo (Sala Tercera) estima que no corresponde con la intención del legislador extender la aplicabilidad de la responsabilidad en estos casos (inexistencia subjetiva). Afirma que para este tipo de situaciones puede recurrirse a la Responsabilidad Administrativa General contenida en el artículo 121 constitucional.

Se observa así una diferencia bastante marcada, ya que la limitación para el reconocimiento de responsabilidad por la causal estudiada en este trabajo de grado en el Estado español es mucho más estricta y cierra las puertas a masivas demandas contra ese Estado, limitando también la fuga de recursos a través de sentencias condenatorias que reconozcan la obligación de indemnizar los perjuicios causados por privación injusta de la libertad de un imputado que es declarado inocente.

\section{Sobre la tendencia sobre responsabilidad estatal por privación injusta de la libertad en Chile}

La responsabilidad estatal propiamente dicha fue incorporada a partir de la expedición de la Constitución chilena, en el año 1980. Específicamente en su artículo 19 numeral 7 del cual se lee: "Una vez dictado el sobreseimiento definitivo o sentencia absolutoria, el que hubiese sido sometido a proceso o condenado en cualquier instancia por resolución que la Corte Suprema de Justicia declare injustificadamente errónea o arbitraria, tendrá derecho a ser indemnizado por el Estado de los perjuicios 
patrimoniales y morales que haya sufrido". También se refiere a la obligación de indemnizar en el artículo 38 inciso 2 por causa de la responsabilidad extracontractual.

Es pues de origen constitucional la obligación del Estado chileno de resarcir los daños causados por el simple hecho de que en su favor y a causa de proceso judicial se dictara sentencia absolutoria, o porque el órgano de persecución e investigación criminal desistiera de continuar con el proceso penal con sobreseimiento definitivo.

\section{Paradigma normativo}

La responsabilidad del Estado por la privación injusta de la libertad se encuentra enmarcada en los artículos 28 y 90 de la Constitución Política de Colombia. El primero de ellos consagra el derecho fundamental a la libertad y prevé la posibilidad de su limitación o restricción, e incluso, la privación de este derecho, mediante la imposición de medidas cautelares de aseguramiento o penas restrictivas o privativas de la libertad, en tanto se cumplan los siguientes requisitos: (i) mandamiento escrito de autoridad judicial competente; (ii) cumplimiento de las formalidades legales; y (iii) la existencia de motivos previamente definidos en la ley.

El artículo 90 de la Constitución Política de 1991 indica que "el Estado responderá por los daños antijurídicos que le sean imputables, causados por la acción o la omisión de las autoridades públicas". Esto significa que para declarar la responsabilidad del Estado es necesario acreditar la existencia de un daño, entendido como la "aminoración patrimonial sufrida por la víctima", el cual debe revestir la característica de ser antijurídico; es decir, que quien lo sufre no se encuentre en el deber jurídico de soportarlo y que ese daño antijurídico resulte imputable a la entidad pública demandada.

La Ley 906 de 2004 no contiene ninguna previsión relacionada con el derecho a la indemnización por la privación injusta de la libertad, por lo que la normatividad vigente a dichos efectos está constituida por los artículos 28 y 90 constitucionales y por los artículos 65 y 68 de la Ley 270 de 1996; sin embargo, los eventos de responsabilidad objetiva consagrados en el derogado artículo 414 del Decreto 2700 de 1991 continúan siendo aplicados por el alto tribunal de lo Contencioso Administrativo, como se explicará en la presente investigación.

\section{Paradigma axiológico}

Los valores que determinan una sociedad en la dimensión axiológica de esta investigación centran especial atención en que la privación legal e injusta de la libertad 
causa un daño antijurídico; debido a que quien lo padece no está obligado jurídicamente a soportarlo, surgiendo para el Estado la obligación de indemnizar, ya que de no hacerlo desconocería su razón de ser. Se presenta una herramienta de investigación, la cual señala el verdadero significado de la responsabilidad extracontractual del Estado por la privación injusta de la libertad, con sus respectivos alcances.

La investigación adopta un enfoque formativo o axiológico, con un alcance de carácter representativo, acudiendo a fuentes doctrinales, normativas y a la unificación jurisprudencial. A partir del análisis de la información obtenida, se determina cómo desde la norma se establecen los lineamientos de la responsabilidad extracontractual del Estado por la privación injusta de la libertad para con sus ciudadanos en Colombia.

\section{LOS TÍTULOS DE IMPUTACIÓN DE RESPONSABILIDAD A CARGO DEL ESTADO}

En los términos del artículo 90 de la Constitución Política, la persona podrá demandar directamente la reparación del daño antijurídico producido por la acción u omisión de los agentes del Estado:

a) Falla del servicio presunta: se debe acreditar que se ha sufrido un perjuicio indemnizable, la existencia de una relación causal con el hecho causante del perjuicio, y es la entidad demandada a quien le queda la posibilidad de exonerarse de toda responsabilidad probando que aunque el perjuicio fue causado por un acto o hecho imputable a ella, obró de manera prudente y con tal diligencia que su actuación no puede calificarse como omisiva, imprudente o negligente en forma tal que dé lugar a comprometer su responsabilidad.

b) Daño especial: consiste en que la Administración debe responder por los daños causados por una actividad completamente legítima, tanto desde el punto de vista sustancial como procedimental. Así, esos daños pueden ser calificados de especiales. Estos daños se fundamentan en el art. 90 de la Constitución Política de Colombia.

c) Riesgos excepcionales: son un supuesto de la responsabilidad objetiva en cuya declaración solo se exonera a la entidad comprometida por fuerza mayor, hecho exclusivo de la víctima o de un tercero; elementos que hacen desaparecer la relación entre la causalidad de la omisión o el hecho generador del daño causado. 
Con estas causas, se abre paso a la posibilidad de que se demande la solicitud de reparación por parte del Estado, pero al mismo tiempo constituyen el lineamiento que tiene el mismo Estado para identificar la procedencia o no de tal reparación a manera de indemnización, a efectos de esta investigación, en lo correspondiente a la privación injusta de la libertad.

\section{RESULTADOS}

Sobre privación injusta de la libertad como generadora de perjuicios y causal de demandas administrativas, la Sección Tercera del Consejo de Estado ha sido fuente jurisprudencial evolutiva, iniciando con una tesis restrictiva de carácter subjetivo, en la que reconoce la obligación del Estado de indemnizar los perjuicios cuando tal privación de la libertad haya sido producto de una "falla del servicio judicial", esto es, que por decisión judicial a la persona se le haya vulnerado injustamente su derecho a la libertad; esto se ajustaba a lo que la Constitución Política antecedente de la de 1991 contenía al respecto.

La segunda tesis en la línea jurisprudencial es de tipo objetivo y se fundamenta en el artículo 414 del Código Penal de 1991. De acuerdo con este, para el cuerpo colegiado la indemnización procede cuando el hecho encuadre en una de las tres causales que el enunciado normativo determina: i) que se decrete absolución porque el sindicado no cometió el hecho, ii) que el hecho no existió o iii) que el hecho no constituía delito en este sistema sin importar el actuar del funcionario judicial, pues lo que se pretende no es verificar solo o culpa de su parte; en este sistema el demandante tenía la carga probatoria y tenía que demostrar el error judicial sobre la base del injusto de la detención (el no cumplimiento de los requisitos del art. 414).

La tercera tesis, que se considera de carácter amplio, determina que la responsabilidad del Estado en demandas por privación injusta de la libertad no se establece de manera limitada por el cumplimiento de alguno de los tres supuestos del mencionado artículo 414, sino que hace viable tal responsabilidad cuando el sindicado es absuelto en aplicación al principio "indubio pro reo". Finalmente, el Consejo de Estado estableció un cuarto sistema en el que, dejando de lado el análisis de cualquier error en el actuar del funcionario judicial y alejándose de la limitación enumerativa de los requisitos contenidos en el artículo 414 del derogado Código de Procedimiento Penal o de la aplicación del indubio pro reo, determinó que cualquier proceso de investigación penal en el que se haya privado de la libertad al sindicado y que este no sea condenado dará lugar a la declaración de la responsabilidad estatal y abrirá las puertas a la obligación del Estado de reparar el perjuicio causado por una detención injusta. 
Si bien es cierto que Estado tiene el deber jurídico de investigar, el ciudadano no tiene la obligación jurídica de soportar la privación de la libertad, que es uno de los derechos de mayor protección en el Estado social de derecho.

Es oportuno recalcar que la sanción preparatoria de la sentencia condenatoria por responsabilidad frente a la privación injusta de la libertad no deslegitima ni el actuar del agente judicial, ni el proceso judicial en sí mismo; sino que establece la configuración de un perjuicio o afectación injusta, en la medida en que los ciudadanos no están obligados a soportar la vulneración de sus libertades personales en el desarrollo de los procesos judiciales que tienen como desenlace la desvinculación o absolución del procesado.

En principio, el régimen aplicable es el objetivo, así lo ha precisado la Subsección del Consejo de Estado, por lo que no es necesario establecer si hubo falla en la prestación del servicio. De tal manera, no se tendrá en cuenta que la declaratoria de responsabilidad por privación injusta provenga de la ilegalidad, falla o yerro en la decisión que ordena la privación preventiva de la libertad, sino que se fundamentará en el sobreseimiento a posteriori, por lo que no es necesario realizar un análisis de la actuación defectuosa de las entidades demandadas, solo basta con verificar si:

- Se impuso en contra de los accionantes una medida restrictiva de la libertad en el marco de un proceso penal.

- El proceso culminó con decisión favorable a la inocencia.

- El daño y los consecuentes perjuicios surgidos de la restricción de la libertad originan obligación de reparar.

Sobre el particular, la jurisprudencia de las diferentes subsecciones de la Sección Tercera no ha sido pacífica. Recientemente, se han conocido sentencias en las que se aplica el régimen subjetivo bajo el título de imputación de falla del servicio, donde incluso en algunos casos se ha exonerado de responsabilidad al Estado por "culpa exclusiva de la víctima", aun cuando los procesos penales han terminado con absolución.

Lo anterior indica que el análisis del tema de la referencia es tan amplio que se vislumbran futuras sentencias hito, con posiciones más específicas y enriquecedoras para la solución de los casos en que se demande del Estado la reparación por la limitación de los derechos, sobre todo el de la libertad, de quien se ha visto vinculado a una investigación criminal y que termina siendo exonerado de responsabilidad bien sea por desvinculación anticipada a sentencia o por la sentencia absolutoria resultante del proceso penal. 


\section{CONCLUSIONES}

Se puede resumir la tendencia jurisprudencial del Consejo de Estado Sección Tercera sobre la responsabilidad estatal en casos de privación injusta de la libertad con los siguientes conceptos, a saber:

1. Exoneración de responsabilidad estatal en casos de privación legal e injusta de la libertad: cuando por captura legal y con la verificación de los supuestos requeridos para decretar la medida de aseguramiento privativa de la libertad, esta es impuesta y hay una posterior condena del indiciado.

2. Responsabilidad estatal por falla del servicio: por ejemplo cuando sin la observancia de los requisitos legales, se impone medida preventiva privativa de la libertad. Esto considera defectuoso el funcionamiento de los entes judiciales.

3. Responsabilidad estatal a título de falla del servicio o daño especial: cuando se absuelve al indiciado por no haber cometido el delito, por no haber existido el ilícito o por no constituirse en delito la acción investigada, después de haber permanecido privado de la libertad. Privación que se considera una carga que no debía soportar.

4. Responsabilidad estatal a causa de privación legal e injusta: el juez impone la medida de aseguramiento privativa de la libertad con total observancia de los requisitos legales, pero con el resultado de absolución del indiciado por no poder probarse su responsabilidad en la acción investigada.

\section{RECOMENDACIONES}

La sujeción de los procedimientos legales a los principios fundamentales del derecho es la vía más segura para evitar fallas o vulneraciones de derechos que a posteriori generen la obligación estatal de asumir responsabilidades y reparar daños por vía de indemnización de perjuicios, bien sean estos patrimoniales o extrapatrimoniales.

Los sujetos procesales siempre esperan el menor desgaste y más si se trata del sujeto pasivo de un proceso penal, quien espera la aplicación más justa de los principios y garantías. Así las cosas, no será paciente frente a excesos o errores que le signifiquen soportar cargas que el conglomerado social no está en obligación de soportar. El ente acusador debe restringirse a la aplicación estricta de las medidas que limiten los derechos fundamentales conforme a los requisitos normativos y a la sujeción rigurosa de los principios que los protegen. 
Podría presumirse desconocimiento o falta de capacitación de los funcionarios judiciales, de manera que la recomendación principal consistiría en la implementación de capacitaciones, actualizaciones en los temas que les preparen para actuar diligente, cuidadosa y oportunamente con atención a la protección de los derechos fundamentales del indiciado, a fin de observar el régimen de responsabilidad objetiva, prevenir el daño antijurídico y disminuir los índices de demandas y condenas de responsabilidad estatal por causa de la privación injusta de la libertad. La disminución de estos procesos y condenas se traducirá en menor gasto de los recursos estatales para asumir las indemnizaciones y podrán usarse más provechosamente en inversión social.

La recomendación es también un cambio de cultura en los funcionarios judiciales para que prevengan los mencionados daños antijurídicos como el de la privación injusta de la libertad, haciendo uso de las otras medidas de aseguramiento; es dejar atrás la cultura carcelaria que, entre otras cosas, ha generado saturación de los centros penitenciarios más allá de su capacidad.

\section{REFERENCIAS}

Consejo de Estado. Sentencia 13168 de 2006. (CP Mauricio Fajardo Gómez; diciembre 4 de 2006).

Consejo de Estado. SentenciA 15128 de 2007. (CP Ramiro Saavedra Becerra; diciembre 5 de 2007).

Consejo de Estado. Sección Tercera. Sentencia 16075 de 2008 (CP Ruth Stella Correa Palacio; marzo 6 de 2008).

Eduardo García De Enterría. CURSO DE DERECHO ADMINISTRATIVO. 10. edición. Editorial Thomson Civitas. (2006).

Jaime Orlando Santofimio Gamboa. TRATADO DE DERECHO ADMINISTRATIVO. 3. ${ }^{a}$ edición. Universidad Externado de Colombia. (2007).

Joaquín García Morillo. LOS DERECHOS DE LA LIBERTAD. Tirant lo Blanch. (1995).

Luis Guillermo Serrano Escobar. RESPONSABILIDAD DEL ESTADO POR PRIVACIÓN INJUSTA DE LA LIBERTAD. Ediciones Doctrina y Ley. (2005). 
16 Tendencia actual de la responsabilidad estatal en procesos de privación injusta de la libertad

Martín Bermúdez. PRIVACIÓN IN JUSTA DE LA LIBERTAD. Ediciones Librería del Profesional. (1998).

Néstor Iván Osuna Patiño. Apuntes sobre el concepto de derechos fundamentales. TEMAS DE Derecho Público N.․ 37. Instituto de Estudios Constitucionales Carlos Restrepo Piedrahita, Universidad Externado de Colombia. (1997).

Ricardo Hoyos Duque, María Victoria Zambrano y Luis Fernando Jaramillo Bedoya. Responsabilidad del Estado por la privación injusta de la libertad. REVISTA PROLEGómENOS, DERECHOS Y VALORES 9. Enero-junio 2006. 